\title{
FINITE ELEMENT ANALYSIS AND PARAMETRIC STUDY OF CURVED CONCRETE BOX GIRDER USING ABAQUS SOFTWARE
}

\author{
Nila P Sasidharan ${ }^{1}$, Basil Johny ${ }^{2}$ \\ ${ }^{1}$ M. Tech. Student, Department of Civil Engineering, Ilahia College of Engineering and Technology, Kerala \\ ${ }^{2}$ Assistant Professor, Department of Civil Engineering, Ilahia College of Engineering and Technology, Kerala
}

\begin{abstract}
The horizontally curved bridges are becoming the norm of highway interchanges and urban expressways as a result of complicated geometrics, limited rights of way, and traffic mitigation. This type of superstructure has gained popularity because it addresses the needs of transportation engineering. A study of box girder curved in plan with rectangular cross-section has been carried out in the present investigation. The finite element software ABAQUS is used to carryout analysis of these box girders. The analysis is carried out for the dead load, super imposed dead load and live load of IRC Class A loading. The paper presents a parametric study of curved box girders by varying span and radius of curvature and by keeping the span to depth ratio constant. The parametric investigations performed on curved box girders helps to evaluate the effects of different parameters on the behavior of the girder. This study would enable bridge engineers to better understand the behavior of curved concrete box girders.
\end{abstract}

Key Words: Curved concrete box girder, ABAQUS

\section{INTRODUCTION}

Box girders are quite common in highway and bridge systems due to their structural efficiency, better stability, serviceability, economy of construction and pleasing aesthetics. A box girder bridge is a type of bridge in which the main beams comprises of girders in the shape of a hollow box. Box girder bridges are commonly used for highway flyovers and for modern elevated structures of light rail transport. A box girder is particularly well suited for use in curved bridge systems due to its high torsional rigidity. High torsional rigidity enables box girders to effectively resist the torsional deformations encountered in curved thinwalled beams.

The Box-Girders can be of different forms and geometry. Box girder decks are cast-in-place units that can be constructed to follow any desired alignment in plan, so that straight, skew and curved bridges of various shapes are common in the highway system.

The analysis and design of box-girder bridges are very complex because of its three dimensional behavior consisting of torsion, distortion and bending in longitudinal and transverse directions. There are many methods for analysis of box girders. But in most of the methods the exact nature of curved box girders are not taken into account because of the assumptions made in the analysis. The most rigorous way to analyze such a complex system and obtain detailed results is through finite element modeling. Available research works on box girder bridges are discussed here.

Gupta P. K et al. [1] conducted parametric study on behavior of box-girder bridges using finite element method with SAP 2000. It is found that the rectangular section is superior to other two sections. Ashish B Sarode et al. [2] conducted a parametric study of horizontally curved box girders for torsional behavior and stability. It is observed that there is no significant variation in the bending moments and the shear forces for DL, SIDL and LL for the specific span length with different radii. Amit Saxena et al. [3] conducted a comparative study of the analysis and design of T-beam girder and box girder superstructure on the basis of moment of resistance of section, shear capacity of section and cost effective solution from both T-Beam and Box Girder Bridge. They found that the cost of concrete and quantity of steel for T- Beam girder is less compared to two cell box girder bridges.

Zdenek P. Bazant, Qiang Yu, Guang-Hua Li [4] studied the excessive long-time deflections of pre stressed box girders and came to the conclusion that the box girders are thickwalled shells for which the beam type analysis is inadequate. Three-dimensional analysis must be used. Chirag Garg \& Siva Kumar M. V. N [5] studied the basic design of a precast segmental box girder bridge and concluded that the more stable structure of the two cases for this box shape is the modified one with elongated overhanging beams and thickened joints. Kamaitis $Z$ [6] observed that a sufficient cracking resistance of existing bridge superstructures can be achieved by increasing the dimensions of cross-section of box girder webs.

\section{PROBLEM DEFINITION}

In this study three dimensional models of curved concrete box girders are analyzed to carry out the comparison of reaction, bending stress, shear stress and mid span deflection response of curved concrete box girder using parametric 
study by varying span and radius of curvature. The aim of this study is to better understand the behavior of curved concrete box girders by using a finite element software ABAQUS. The main objectives of this study are

- To carry out the analysis of three-dimensional finite element models of box girder using the finite element computer program "ABAQUS"

- $\quad$ To compare the variation of bending stress, shear stress and mid span deflection due to variation in curvature.

- To find the most suitable radius of curvature for different spans based on their deflection pattern

The cross section for the model is adopted from a recent study on curved box girder bridges [2]. A Single-cell rectangular type box girder having $7.5 \mathrm{~m}$ width, 2-Lanes carriageway with overall deck width of $8.5 \mathrm{~m}$ is considered. The thickness of top deck slab is $240 \mathrm{~mm}$ at middle, $300 \mathrm{~mm}$ at web and $200 \mathrm{~mm}$ at ends. The thickness of both soffit slab and webs are $240 \mathrm{~mm}$. The overall Span lengths considered are $20 \mathrm{~m}, 30 \mathrm{~m}$ and $40 \mathrm{~m}$. Seven different radius of curvature such as $75 \mathrm{~m}, 90 \mathrm{~m}, 100 \mathrm{~m}, 150 \mathrm{~m}, 200 \mathrm{~m}, 250 \mathrm{~m}$ and $300 \mathrm{~m}$ are considered. A span to depth ratio of 16 is adopted. The depths for different spans are as follows:

Table -1: Depths corresponding to the lengths for $\mathrm{L} / \mathrm{D}$ ratio of 16

\begin{tabular}{|l|l|l|l|l|}
\hline Span(m) & 20 & 25 & 30 & 40 \\
\hline Depth(m) & 1.25 & 1.5625 & 1.875 & 2.5 \\
\hline
\end{tabular}

Figure shows the cross sectional view of the simply supported box girder bridge model used for the parametric study.

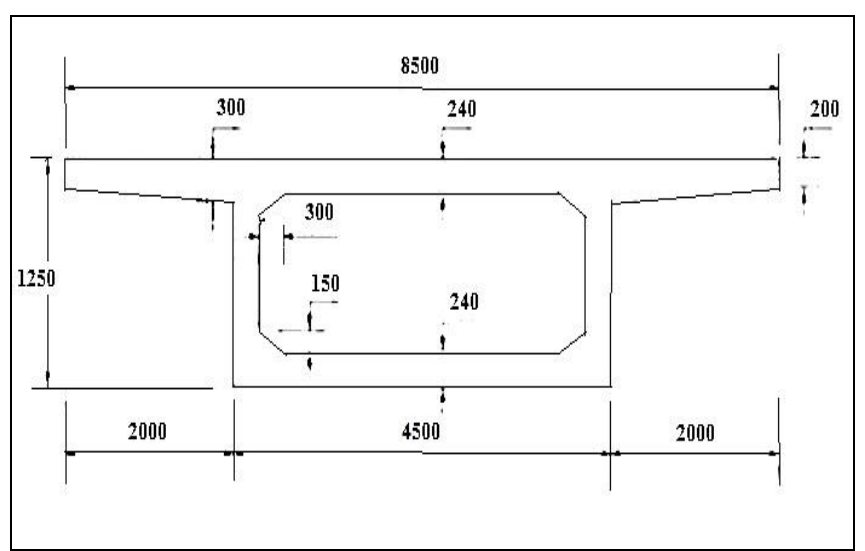

Fig -1: Cross-sectional dimensions of Rectangular Box Girder

Twenty one models are created using ABAQUS by varying the span length and radius of curvature. The models are created in ABAQUS by varying the rotation angles. The different models are designated by their span length and radius of curvature. For example the model with span length $20 \mathrm{~m}$ and radius of curvature $75 \mathrm{~m}$ is designated as $20 \mathrm{M} 75$.

\subsection{Member Properties}

The box girder model considered for analysis is a concrete box girder. The various material properties considered are given in the table.

Table -2: Material properties

\begin{tabular}{|l|l|}
\hline Properties & Values \\
\hline Weight /unit volume & $2549.275 \mathrm{~kg} / \mathrm{m}^{3}$ \\
\hline Young's modulus (E) & $27.386 \mathrm{e}^{9} \mathrm{~N} / \mathrm{m}^{2}$ \\
\hline Poisson's ratio (v) & 0.2 \\
\hline Grade of concrete & $\mathrm{M} 30$ \\
\hline Grade of steel & $\mathrm{Fe} 415$ \\
\hline
\end{tabular}

\subsection{Loads}

The loads that are considered on the superstructure of a typical box girder bridges are listed below.

Dead load: The self-weight of the structure is applied to the structure as dead load

Super imposed dead load: The super imposed dead load applied to the structure is $1760 \mathrm{~N} / \mathrm{m}^{2}$ by assuming the thickness of wearing coat as $80 \mathrm{~mm}$ with a unit weight of $22 \mathrm{kN} / \mathrm{m}^{3}$

Live load: The live load is considered as per IRC: 6-2010 [10]. The maximum wheel load in IRC Class A loading is considered for analysis of box girders. The impact factor for IRC Class A loading is also considered.

Table -3: Impact factors for different spans

\begin{tabular}{|l|l|l|l|}
\hline Span $(m)$ & 20 & 30 & 40 \\
\hline Impact factor & 0.173 & 0.125 & 0.098 \\
\hline
\end{tabular}

Group Loading Combinations: The combinations considered are

- DL+SIDL

- $\mathrm{DL}+\mathrm{SIDL}+\mathrm{LL}$

\section{STRUCTURAL ANALYSIS}

ABAQUS is a highly sophisticated, general purpose finite element program, designed primarily to model the behavior of solids and structures under externally applied loading. A part of the box girder bridge which is horizontally curved in plan is considered. Its slab is monolithically constructed with the concrete box girder. The girder is a single cell box girder having rectangular cross-section. The models created with ABAQUS are shown in figure given below. 


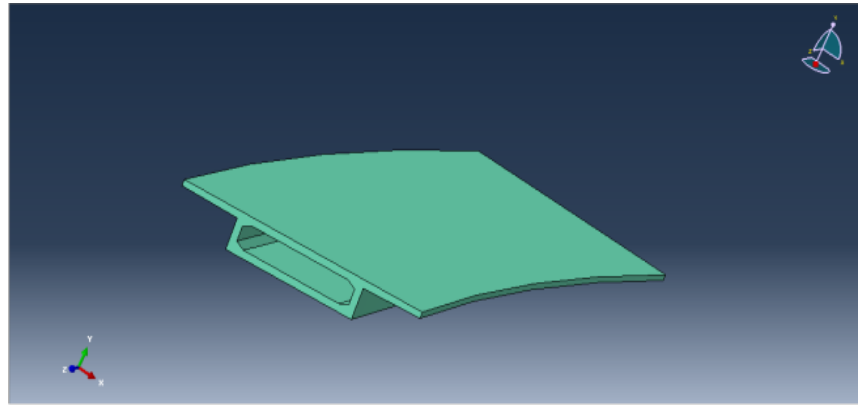

Fig -2: 3D view of rectangular curved box girder

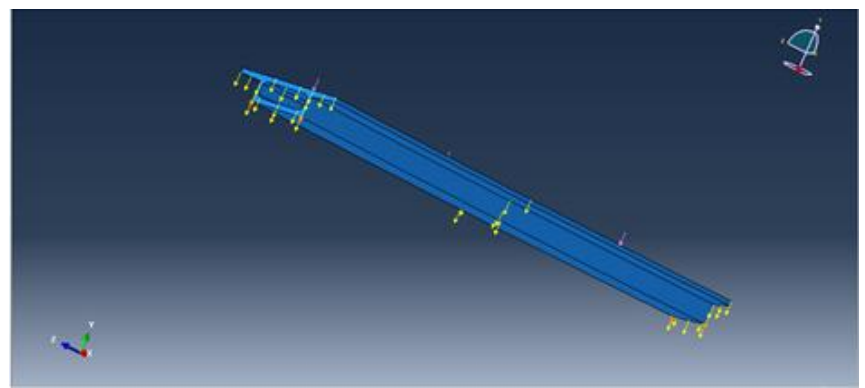

Fig -3: Box girder with boundary conditions (hinged)

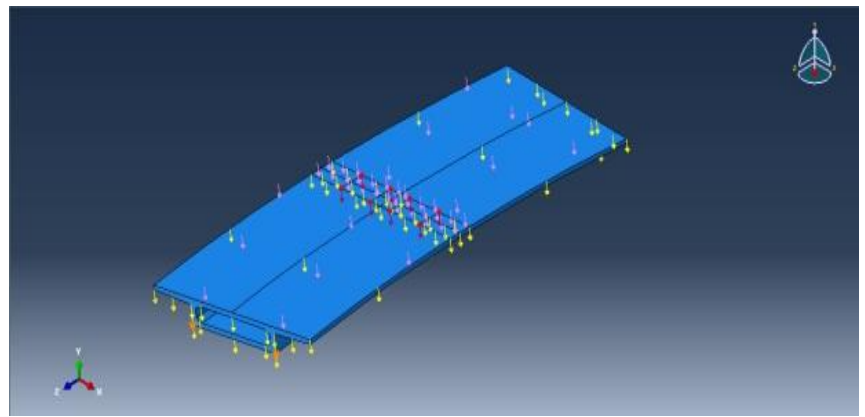

Fig -4: Box girder with load application

\section{RESULTS AND DISCUSSION}

The horizontally curved box girders of 20 to $40 \mathrm{~m}$ span lengths in combinations with radius of $75 \mathrm{~m}, 90 \mathrm{~m}, 100 \mathrm{~m}$, $150 \mathrm{~m}, 200 \mathrm{~m}, 250 \mathrm{~m}, 300 \mathrm{~m}$ are analyzed and the diagrams obtained for deflection for the two load combinations are presented. The deflection contours of box girders for $20 \mathrm{~m}$, $30 \mathrm{~m}, 40 \mathrm{~m}$ spans for $75 \mathrm{~m}$ radius of curvature are shown below.

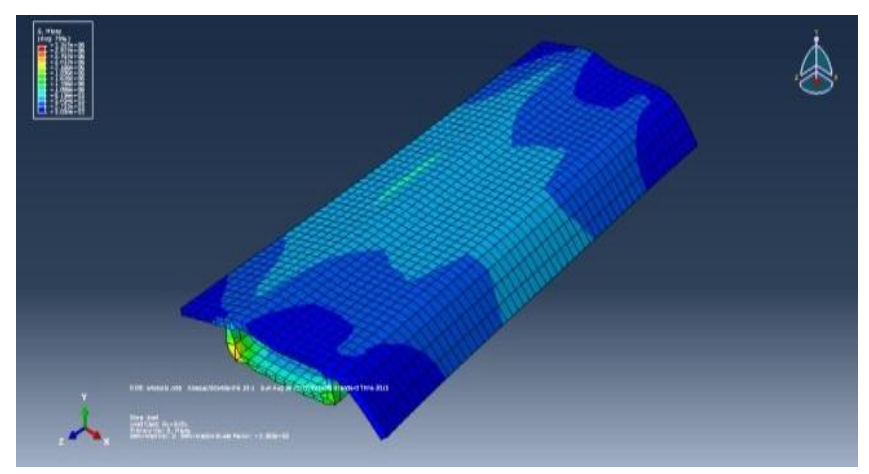

Fig -5: Deflection diagram

(Span 20m, Radius of curvature-75m)

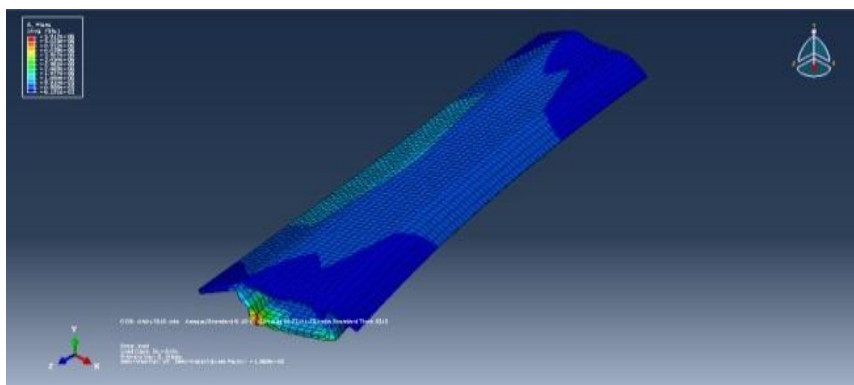

Fig -6: Deflection diagram

(Span 30m, Radius of curvature-75m)

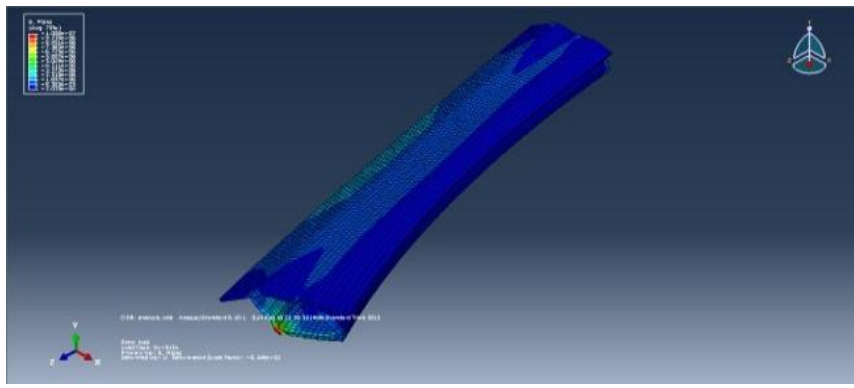

Fig -7: Deflection diagram

(Span 40m, Radius of curvature- $75 \mathrm{~m}$ )

The maximum values of reaction, bending stress, shear stress and mid span deflection for various span length and radii are compared. The variations are shown in the following graphs.

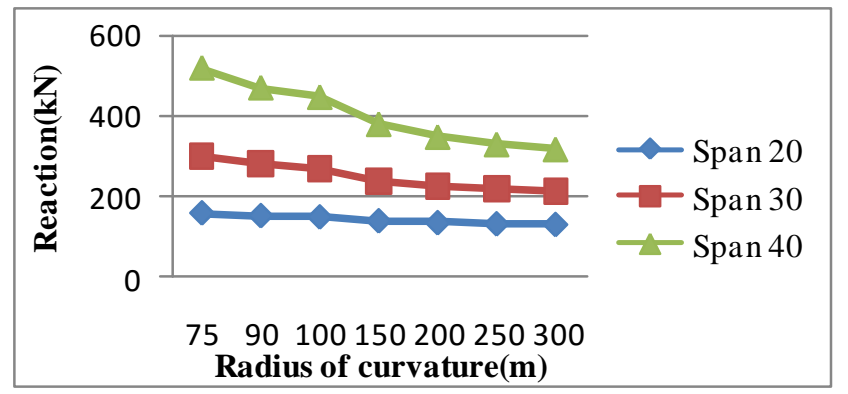

Chart -1: Variation in reaction against span radius $(\mathrm{dl}+\mathrm{sidl})$

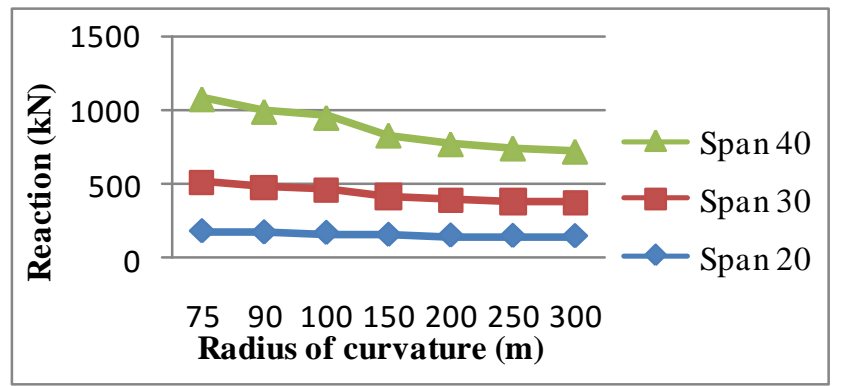

Chart -2: Variation in reaction against span radius $(\mathrm{dl}+\mathrm{sidl}+\mathrm{ll})$

It is observed that the reaction values are decreasing with increase in radius of curvature and with decrease in span length. From $150 \mathrm{~m}$ to $300 \mathrm{~m}$ radius the slope of the curve is gentle. 


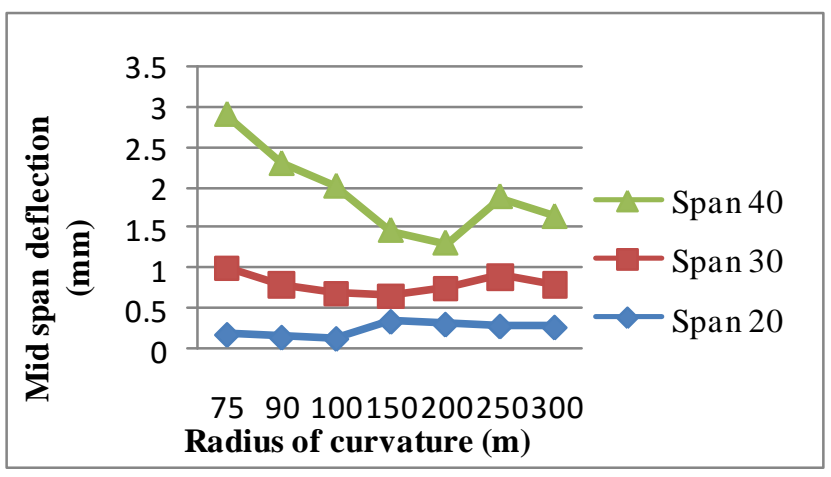

Chart -3: Variation in Displacement against span radius $(\mathrm{dl}+$ sidl $)$

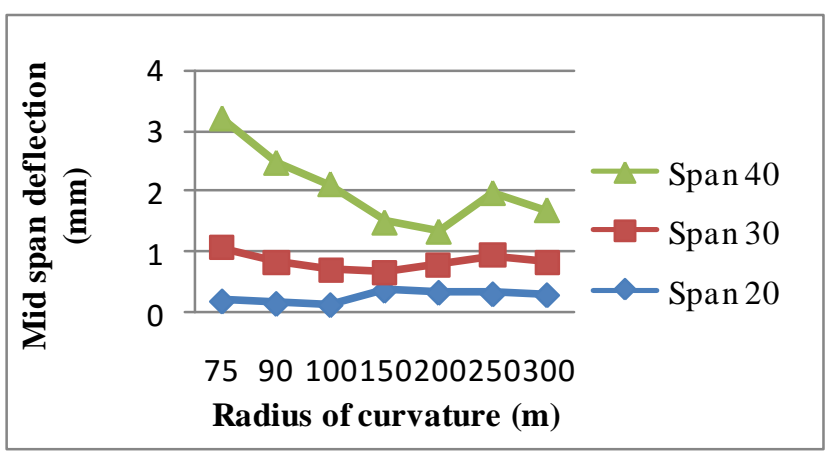

Chart -4: Variation in Displacement against span radius $(\mathrm{dl}+\mathrm{sidl}+\mathrm{ll})$

The graph plotted between mid-span deflection and radius of curvature shows that mid span deflection is also decreasing with decrease in radius of curvature. It is observed that for $40 \mathrm{~m}$ span the mid span deflection is minimum at radius of curvature equal to $200 \mathrm{~m}$. But for $30 \mathrm{~m}$ span, the minimum is observed at $150 \mathrm{~m}$ radius of curvature. In the case of $20 \mathrm{~m}$ span, the mid span deflection is minimum at a radius of $100 \mathrm{~m}$.

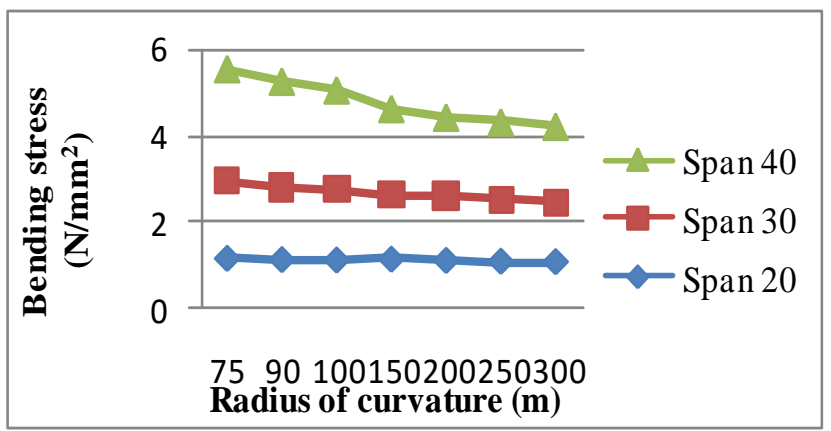

Chart -5: Variation in bending stress against span radius $(\mathrm{dl}+\mathrm{sidl})$

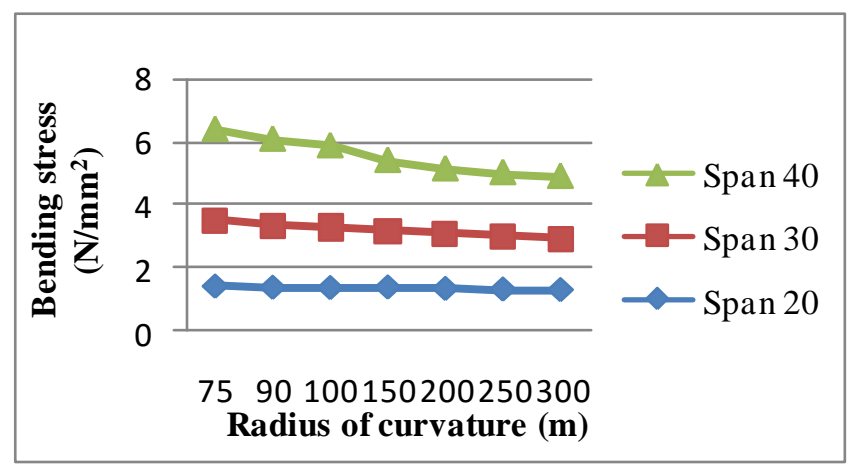

Chart -6: Variation in bending stress against span radius $(\mathrm{dl}+\mathrm{sidl}+\mathrm{ll})$

The bending stress decreases with increase in radius of curvature and with decrease in span. With increase in span the slope of the curve increases. So it can be observed that if span increases, large radius of curvature will give minimum bending stress.

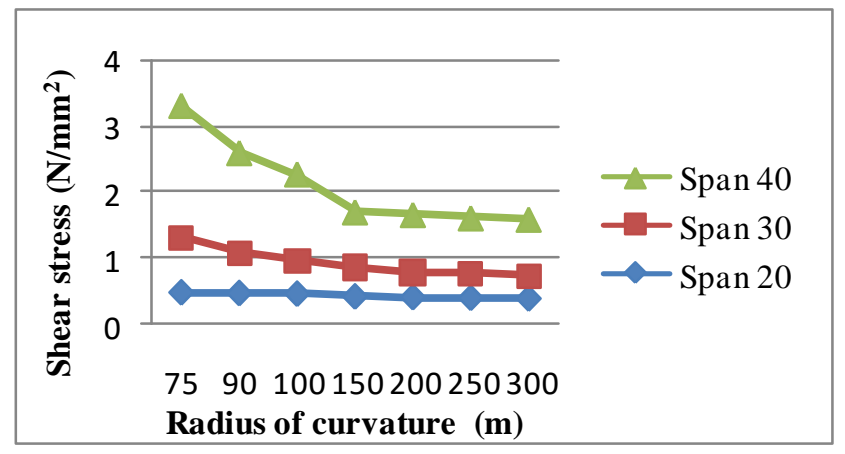

Chart -7: Variation in Shear stress against span radius $(\mathrm{dl}+$ sidl $)$

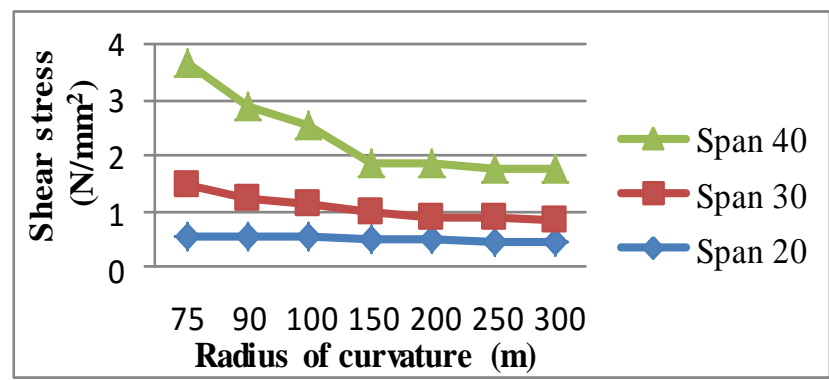

Chart -8: Variation in Shear stress against span radius $(\mathrm{dl}+\mathrm{sidl}+\mathrm{ll})$

As observed in the above cases shear stress also decreases with increase in radius of curvature and with decrease in span length. From the graph it is clear that the variation in shear stress almost remains the same with increase in radius of curvature from $150 \mathrm{~m}$ onwards.

\section{CONCLUSION}

The analysis of various curved box girder models are carried out in ABAQUS software by varying span and radius of curvature. The span to depth ratio is kept constant. The models are created by varying the depth according to a span 
to depth ratio of 16 . The variations in reactions, bending stress, shear stress and mid span deflections are observed by conducting the parametric study. From the results obtained after the analysis of curved single cell rectangular box girder, the following conclusions are made

- The graph plotted between reaction and radius of curvature shows that reaction decreases with increase in radius of curvature and with decrease in span length. So the minimum reaction can be obtained by increasing the radius of curvature.

- If minimum deflection is the criteria for selecting a particular radius of curvature, it can be concluded that for $40 \mathrm{~m}$ span the mid span deflection is minimum at radius of curvature equal to $200 \mathrm{~m}$. But for $30 \mathrm{~m}$ span, the minimum is observed at $150 \mathrm{~m}$ radius of curvature. In the case of $20 \mathrm{~m}$ span, the mid span deflection is minimum at a radius of $100 \mathrm{~m}$.

- The bending stress decreases with increase in radius of curvature. For $20 \mathrm{~m}$ span bending stress remains the same with respect to radius of curvature. It is better to use radius of curvature below $200 \mathrm{~m}$ as span increases to get maximum bending strength.

- The decrease in radius of curvature will increase the shear stress. Also with increase in span shear stress increases. For each span considered, the shear stress distribution is uniform above $150 \mathrm{~m}$ radius of curvature.

\section{REFERENCES}

[1]. Gupta P. K, Singh K K and Mishra A. "Parametric study on behaviour of box-girder bridges using finite element method", Asian journal of civil engineering, Vol. 11, No. 1, 2010.

[2]. Ashish B Sarode and G R Vesmawala, "Parametric Study of Horizontally Curved Box Girders for Torsional Behavior and Stability", International Refereed Journal of Engineering and Science, Vol. 3, January 2014

[3]. Amit Saxena and Dr. Savita Maru. "Comparative Study of the Analysis and Design of T-Beam Girder and Box Girder Superstructure", International Journal of Research in Engineering \& Advanced Technology, April-May, 2013.

[4]. Zdenek P. Bazant, Qiang Yu and Guang-Hua Li. "Excessive Long-Time Deflections of Pre stressed Box Girders. I: Record-Span Bridge in Palau and Other Paradigms", Journal of structural engineering, June 27, 2012.

[5]. Chirag Garg \& Siva Kumar M. V. N . "Study of basic design of a precast segmental box girder bridge", International journal of civil engineering, May 2014.

[6]. Kamaitis Z. "The causes of shear cracking in prestressed concrete box-girder bridges". Journal of civil engineering and management, November 1, 2012.

[7]. Shushkewich K. "Approximate Analysis of Concrete Box Girder Bridges." J. Struct. Eng., 114 (7), 16441657., July 1, 1988

[8]. Hodson D, Barr P, and Halling M. "Live-Load Analysis of Posttensioned Box-Girder Bridges." J. Bridge Eng., 17(4), 644-651, August 27, 2011
[9]. Notkus A. J. and Kamaitis Z, "Evaluation of shear stresses in the webs of segmental box-girder concrete bridges". Journal of civil engineering and management, July 26, 2012

[10]. IRC: 6- 2010, Standard specifications and code of practice for road bridges, Section- II: Loads and stresses

[11]. IRC: 21- 2000, Standard specifications and code of practice for road bridges 